\title{
HONORABLE MENTION
}

\section{Elegy in a Stairwell \\ RDB 1906-1985}

It wasn't my regular day, but when I arrived he lay on the landing in jacket and tie dressed for the occasion.

\section{Step by step}

his discoverers left.

"The staff think he slipped," the young officer said.

"They called right away. Where he was going ... Or why ..."

The jacket and tie he would wear the rest of my life,

the mask of good-bye.

“. . . I said, 'In the interests of time, would you mind pronouncing your father dead?'”

More sons have killed their fathers than done so, I thought, drawing my stethoscope.

Or is it the same, one myth twisting in the brain, one nightmare of estrangement?

Listening,

I became another doctor. 